\title{
Procedimentos de autoria na produção de textos escritos
}

\begin{abstract}
Márcia Vescovi Fortunato, licenciada em Letras e doutora em Educação pela Universidade de São Paulo na área de Linguagem e Educação, é professora do Instituto Superior de Educação ISE Vera Cruz e coordenadora do curso de pós-graduação "Formação de Escritores e Especialistas em Produção de Textos Literários" na mesma instituição.
\end{abstract}

Contato: mvfortunato@ig.com.br

\section{Resumo}

0 objetivo deste estudo foi descrever os procedimentos de autoria em uso durante o processo de produção de textos, a partir do momento em que se apresenta ao escritor uma demanda pela produção de um texto escrito. Para a realização desse propósito, este trabalho fundamentou-se no modelo de processo cognitivo de produção de textos formulado por Linda Flower e John R. Hayes e na concepção de autoria proposta por Mikhail Bakhtin. Trata-se de uma investigação de cunho bibliográfico, que descreve procedimentos de autoria no plano teórico, com o propósito de fundamentar e gerar novas pesquisas para o aprofundamento de questões relacionadas ao tema. Palavras-chave: Processo de escrita; procedimento de autoria, produção de texto.

\section{Abstract}

The object of this study was to describe authorship procedures used during text production process since the moment a writing task is presented to the writer. In order to realize this purpose, this work is based on Linda Flower e John R. Hayes's cognitive process model of writing and on Bakhtin's notion of authorship. It is a bibliographical exploration which theoretically describes authorship procedures, with the purpose of substantiating and generating new researches in order to deepen the questions related to the subject.

Keywords: Writing process; authorship procedure; text production. 


\section{Processo de produção de texto e autoria}

A partir de 1980, em substituição aos modelos behavioristas, estudos no campo da produção de textos fundamentados nas ciências cognitivas concentraram sua atenção em três grandes vertentes: a descrição do processo desenvolvido durante a composição de textos escritos, as estratégias utilizadas pelos escritores e os fatores que influenciavam essa produção.

As novas abordagens compreendiam os textos como resultado de eventos dinâmicos nos quais as representações mentais de leitores e escritores interagem com o contexto social e as convenções discursivas. São dessa época os ensaios notáveis de Flower e Hayes, The cognition of discovery: defining a rhetorical problem, de 1980 (Flower; Hayes, 1994), e A Cognitive Process Theory of Writing, de 1981 (Flower; Hayes, 1981), que descrevem o modelo de processo de produção de texto que será objeto de estudo neste artigo.

Sommers (1994), em ensaio publicado em 1980, observa que os modelos de escrita propostos pelos pesquisadores até aquele momento eram, em sua maioria, concebidos linearmente. Em suas palavras:

\begin{abstract}
Although various aspects of the writing process have been studied extensively of late, research on revision has been notably absent. The reason for this, I suspect, is that current models of the writing process have directed attention away from revision. With few exceptions, these models are linear; they separate the writing process into discrete stages (p. 75)'.
\end{abstract}

Essa concepção do processo de escrita, segundo Sommers (1994), abstraía um modelo a partir do que se conhecia acerca da fala, descrevendo o processo como uma sequência de estágios que iam da escrita para a reescrita, entendidas como sendo duas atividades sucessivas e temporalmente distintas, ou como a sucessão de processos de concepção-incubação-produção.

In these linear conceptions of the writing process revision is understood as a separate stage at the end of the process - a stage that comes after the completion of a first or second draft and one that is temporally distinct from the prewriting and writing stages of the process (Sommers, 1994, p. 75)².
1. "Embora vários aspectos do processo de escrita tenham sido estudados fartamente nos últimos tempos, pesquisas sobre a revisão em particular têm estado ausentes. A razão para isso, suspeito, é que os modelos atuais de processo de escrita ignoram a revisão. Com poucas exceções, esses modelos são lineares e separam o processo de escrita em estágios distintos" (tradução da autora).

2. "Nessas concepções lineares de processo de escrita, a revisão é compreendida como um estágio separado no final do processo - um estágio que vem depois de concluído o primeiro ou o segundo rascunho e que é temporalmente distinto dos estágios da pré-escrita e da escrita" (Idem). 
Na perspectiva cognitivista, a escrita não será compreendida como um registro da fala, mas como uma atividade semiótica que tem estatuto próprio e que vai além do exercício gráfico-motor. A produção textual assim concebida constitui um processo de pensamento que ocorre antes, durante e depois da escrita propriamente dita. Além disso, a ênfase é posta na dinâmica não linear das diversas ações que um escritor realiza ao escrever.

\section{1. 0 modelo de Flower e Hayes}

Flower e Hayes $(1994,1981)$ realizaram investigações acerca do processo cognitivo desencadeado durante a produção de textos e observaram que todo o processo se desenvolve sob dois tipos de informação: o conhecimento a que se tem acesso na memória de longo prazo (os conceitos que envolvem o tópico, a estrutura do discurso e os conhecimentos sobre como se escreve) e a que provém do ambiente em que se dá a tarefa de representação (a motivação do escritor, as características do tópico e/ou do público leitor).

A escrita é compreendida nesse modelo como um processo de resolução de problemas que requer procedimentos específicos. Para os autores desse estudo, resolver um problema implica a mobilização de muitas habilidades durante a operação de escrita de um texto. $\mathrm{E}$, embora sempre envolva procedimentos exploratórios abertos, como a escrita livre ou os devaneios, esse processo não é acidental.

Segundo Flower e Hayes (1981), o ato de escrita envolve três elementos principais, que estão representados nas três unidades do modelo: o contexto de produção ["task environment"], a memória de longo prazo do escritor ["the writer's long-term memory"] e os processos de escrita ["writing processes"].

0 contexto de produção inclui tudo o que está fora do escritor: o problema retórico (que demanda a produção) e o texto escrito (a parcela do problema que já foi resolvida). A memória de longo prazo envolve o conhecimento não somente sobre o tópico (conteúdo semântico), mas sobre a audiência (leitor) e a composição de textos (conhecimentos linguísticos). 0 terceiro elemento constitui o processo de escrita propriamente dita, que se desenvolve por meio de atividades de planejamento, redação e revisão. Ao escrever, os escritores monitoram o processo em andamento e seu progresso com base na situação retórica e nos seus objetivos. 
Dessa forma, o processo de escrita constitui um conjunto de processos de pensamento distintos que os escritores orquestram e organizam durante o ato de composição.

Esse modelo, embora tenha suscitado muitos outros estudos sobre o tema, foi criticado na década de 1990 por representar a escrita como um processo controlado e racional (Tynjälä; Mason; Lonka, 2001). Essas críticas fundamentavam-se na compreensão de que a escrita também pode ser um processo espontâneo de geração de pensamentos e de construção de sentidos que modifica e desenvolve o próprio pensamento. Ou seja, a escrita não poderia ser compreendida como um processo altamente controlado, pois a produção de pensamento se dá no próprio ato de escrita, de forma espontânea, durante o processo de criação.

0 modelo descrito por Flower e Hayes foi criticado também por esclarecer pouco o caráter de resolução de problemas atribuído ao processo de escrita e por observar apenas o comportamento de escritores experientes, sem fornecer pistas sobre como os principiantes poderiam tornar-se peritos (Molitor-Lubbert, 2009). A hierarquização dos processos foi também objeto de crítica:

\footnotetext{
[...] aos processos de planejamento, de organização e revisão atribuise o mesmo nível de complexidade, enquanto o processo de leitura, que é considerado como uma parte da revisão, se encontra no nível hierárquico do processo de geração. Por causa da falta de uma ligação entre a organização e a revisão, não é possível levar em consideração a realimentação dos processos de planejamento com diferentes produtos intermediários da escrita. Além disso, nesse modelo, não se leva em consideração nenhum efeito que a produção textual escrita poderia ter sobre o conhecimento armazenado na memória de longo prazo (MolitorLubbert, 2009, p. 127).
}

Entretanto, o modelo de Flower e Hayes foi largamente divulgado e apreciado por outros pesquisadores que desenvolveram pesquisas a partir dele, adaptando-o a tarefas específicas ou aprofundando aspectos do processo descrito. Além disso, o próprio Molitor-Lubbert afirmaria, em 2009, que este modelo:

[...] representa uma análise de tarefas úteis para o pesquisador e para o pedagogo. Ele mostra o que os processos cognitivos têm que realizar durante a produção textual escrita e por quais fatores esses processos podem ser influenciados. Do ponto de vista pedagógico, o modelo pode ser aproveitado para prever dificuldades no trabalho cognitivo realizado 
$E$, após a análise de diversos modelos de processo de produção de textos, Molitor-Lubbert (2009)3 avalia que nenhum deles é universal para explicar todos os fenômenos conhecidos da escrita.

Assim sendo, considerando o exposto, tomamos por tarefa a adaptação do modelo de Flower e Hayes para descrever o que chamamos de procedimentos de autoria. Para tanto, partimos do suposto de que todo ato de escrita é um gesto de autoria, porque, qualquer que seja o discurso, escolar, administrativo ou literário, todos eles são construídos por meio de representação simbólica. Além disso, compreendemos que todo texto recebe acabamento estético, porque toda escolha - da palavra à construção sintática, do título ao último parágrafo ou enunciado - implica um posicionamento do autor, uma resposta singular a um objetivo de escrita.

\subsection{A autoria segundo Bakhtin}

Bakhtin (2002), em artigo de 1924, 0 problema do conteúdo, do material e da forma na criação literária, considera a obra literária como produto da transformação sistemática de um conjunto verbal no todo arquitetônico de um evento esteticamente acabado. Esse processo de transformação implica um conteúdo que se origina nos acontecimentos do plano da existência (do real), mas dele é libertado pela forma estética.

Bakhtin compreende o autor não como pessoa física, que habita o mundo real, mas como uma representação. 0 autor-criador, com seu excedente de visão, vê além do mundo representado. Dialoga com outros discursos, com seus personagens, e exerce sua autoria de uma posição definida na obra. Ele conecta o mundo representado ao mundo real porque seu discurso refrata suas posições com relação ao objeto, com relação a outros discursos.

Essa distinção entre autor-criador e autor real é uma proposição recorrente em Bakhtin, apresentada nos ensaios 0 autor e $a$ personagem na atividade estética, escrito na década de 1920 (Bakhtin, 2003a, p. 9) e 0 problema do conteúdo, do material e da forma na criação literária, de 1924 (Bakhtin, 2002), em seu estudo da obra de Dostoiévski (Bakhtin, 2005, p. 184), e, posteriormente, em suas notas de 1959-1961, quando aborda questões relativas ao texto (Bakhtin, 2003c, p. 321-322). Numa dessas abordagens, Bakhtin (2005) diz:
3. Os textos que referenciam a leitura desse autor são, em sua maioria, anteriores a 1980 e não coincidem com os lidos para esta pesquisa, embora abordem o mesmo modelo. 


\begin{abstract}
[...] todo enunciado tem uma espécie de autor, que no próprio enunciado escutamos como o seu criador. Podemos não saber absolutamente nada sobre o autor real, como ele existe fora do enunciado. As formas dessa autoria real podem ser muito diversas. Uma obra qualquer pode ser produto de um trabalho em equipe, pode ser interpretada como trabalho hereditário de várias gerações etc., e apesar de tudo sentimos nela uma vontade criativa única, uma posição determinada diante da qual se pode reagir dialogicamente. A reação dialógica personifica toda enunciação à qual ela reage (p. 184).
\end{abstract}

0 autor-criador é uma das faces do autor real, pessoa física, que se expressa de um ou outro modo sob a imagem de autor que criou. Nesse sentido, esse autor representado ocupa uma posição determinada no discurso, dirige a cena e reage dialogicamente aos personagens e às situações enquanto os cria. Para Bakhtin, o autor real não é percebido pelo leitor do enunciado, apenas o autor que ele representa, o autor-criador, por meio do qual se manifesta. Portanto, o autor-criador é uma possibilidade, um devir do autor real.

A forma, as relações dialógicas, a natureza e a intensidade de intervenção do autor no discurso, entretanto, estão previstas, até certo ponto, nos gêneros discursivos. Essa noção de que os enunciados são estratificados em cada esfera da atividade humana como parte de uma dinâmica social de comunicação encerra uma ideia de que a autoria, de certa forma, tem seus limites prescritos pela construção social do discurso. As possibilidades do subjetivo no enunciado se desenvolvem tendo em vista essa construção social. Assim, a margem de atuação do autor não é ilimitada: há gêneros que suportam mais ou menos o posicionamento do autor, as relações dialógicas, o estilo pessoal.

Essa compreensão é fundamental, pois, uma vez regulada socialmente, a autoria possui procedimentos que podem ser descritos e analisados, vindo a tornar-se, portanto, objeto de conhecimento.

Na visão bakhtiniana, o enunciado é sempre construído como resposta a outro, ainda que essa implicação não seja explícita. Portanto, quando emerge a demanda por um enunciado, o autor já tem uma posição relativa e inicialmente definida com relação ao objeto, no contexto de uma situação comunicativa. Essa demanda é aplicada a um gênero cuja forma composicional o autor reconhece.

Durante a construção do discurso, muitas são as decisões a tomar em função dessa situação inicial: reconhecer e coordenar as vozes que falam, determinar a modalidade discursiva de cada uma, seus tons, seus cronotopos, a natureza das relações dialógicas que 
vão se estabelecer e seu estilo. Todas as decisões vão concretizar o projeto inicial e explorar o posicionamento do autor em relação ao objeto. Todos os procedimentos do autor convergem, assim, para a atribuição de forma ao conteúdo projetado, de modo a traduzir suas intenções discursivas, sua posição relacionada ao objeto e aos outros discursos.

No exercício da autoria, portanto, estão em jogo conhecimentos sobre a linguagem e suas diversas possibilidades estilísticas; sobre o objeto e seu campo de conhecimento; sobre a esfera social e suas práticas discursivas; sobre discursos de outros sobre o mesmo objeto; sobre o interlocutor e suas demandas; sobre o objeto e sobre os gêneros discursivos e suas formas composicionais.

\section{Procedimentos de autoria}

Vamos considerar neste trabalho os procedimentos de autoria decorrentes dos três tipos de atividade demandados pelo processo de escrita: o planejamento, a produção de textos e a revisão, procedimentos recursivos que configuram o processo de escrita em suas estruturas macro e micro. Não há linearidade ou ocorrências predeterminadas entre esses procedimentos. Há possibilidades combinatórias. Cada um atua diferentemente em cada produção de textos, como eventos que se atualizam em diferentes arranjos.

Conforme os modelos de processo de escrita descritos por Flower e Hayes, todo escritor estabelece hierarquias entre as diferentes atividades que exerce durante a composição de um texto e cria um modus operandi para resolver o problema proposto. Entre essas atividades é frequente a interação entre planejamento e demais elementos do processo:

\footnotetext{
Although writers may spend more time in planning at the beginning of a composicion session, planning is not a unitary stage, but a distinctive thinking process which writers use over and over during composing. Furthermore, it is used at all levels, wether writer is making a global plan for a whole text or a local representation of the meaning of the next sentence (Flower e Hayes, 1981, p. 375). ${ }^{4}$
}

Esse tratamento dado ao planejamento flexibiliza a compreensão do modelo, fazendo-o mais plástico para acomodar diferentes processos de escrita. As múltiplas formas como podem se configurar o processo de escrita em função das
4. "Embora escritores possam gastar mais tempo no planejamento no começo da composição, esse não é um estágio unitário, mas um processo específico de pensamento que os escritores usam durante toda a composição. Posteriormente, ele será usado em todos os níveis, se o escritor estiver fazendo um plano global para um texto inteiro ou uma representação local do sentido da próxima sentença" (tradução da autora). 
diferentes operações que o escritor realiza durante a composição de um texto determinam o uso dos procedimentos de autoria em dinâmicas interativas diversas, em função da situação de produção do texto, do padrão de comportamento do escritor e da demanda que deu origem ao texto.

Vamos fazer uso, nos tópicos seguintes, do termo "autor" para designar o "autor criador" tal como o define Bakhtin. 0 termo "escritor" será utilizado quando, mais explicitamente, nos referirmos à pessoa física que escreve - "autor real", segundo Bakhtin - não apenas para designar o profissional da escrita, mas qualquer pessoa que ocupe o seu lugar.

Algumas vezes, ao abordar o processo de produção de um texto, é difícil precisar quando um "escritor" ocupa a posição de "autor", uma vez que é possível ao segundo constituir-se antes mesmo de o texto se configurar materialmente, enquanto ainda está em processo de gestação, de concepção ou planejamento. Portanto, muitas vezes a fronteira entre o autor, figura do discurso, e o escritor, indivíduo da vida real, é tênue. Procuraremos ser claros no uso dessa terminologia, enquanto for possível estabelecer essa distinção.

\subsection{Procedimentos de planejamento}

Durante o planejamento, o escritor projeta ideias a respeito do trabalho a ser realizado e essas representações funcionam como desencadeadoras da escritura do texto. 0 planejamento pode auxiliar o escritor durante todo o processo de produção, uma vez que é o procedimento por meio do qual se elaboram os objetivos que respondem à demanda pelo texto. Esses objetivos supõem certa representação do problema (da tarefa que demanda a composição do texto), do leitor, do autor, do conteúdo semântico e do texto em construção.

A representação, enquanto atividade de planejamento, não é, necessariamente, formulada com palavras, mas por meio de qualquer meio semiótico. É a subjetividade imanente a essas representações que configura a autoria.

Segundo Flower e Hayes (1994) são os objetivos do escritor em relação ao leitor e à tarefa que desencadeiam a escrita. Os demais objetivos decorrem desses. 0 que é perfeitamente compreensível, pois saber por que escrevemos (o problema a resolver) e para quem escrevemos (qual o leitor presumido) é o mote de que precisamos para desenvolver uma série de outras representações: 
qual será o conteúdo abordado, que gênero textual mais bem cumpre essa tarefa, qual será o posicionamento do autor e outros objetivos, decorrentes dessas primeiras decisões, é que vão manter o processo de produção de texto em andamento.

Portanto, planejar implica tecer, primeiramente, representações do problema e das suas possíveis soluções. Depois, à medida que o texto avança, outros procedimentos são ativados e uma cadeia complexa de ações se constrói. 0 planejamento é um procedimento que funciona durante o processo toda vez que uma nova representação exiǵe reformulação dos objetivos ou proposição de novos. Assim é que o planejamento e a revisão funcionam como procedimentos "irmãos": ao avaliar o texto já escrito, a todo momento, o escritor pode tecer novas representações para o problema e repensar os objetivos iniciais ou desdobrá-los em outros que vão ativar nova sequência de escrita.

Desse modo, é possível pensarmos que as representações se alteram o tempo todo, alimentadas por informações que coletamos em nossa memória, no contexto de produção, no próprio texto e na retomada do problema inicial. Essas reformulações especificam e esclarecem os objetivos, de modo a tornar o processo de decisões mais ágil. Assim, é possível compreender que, mesmo ao decidir pelo uso de um vocábulo, por exemplo, o escritor se reporta aos objetivos traçados para ajustar sua escolha.

De acordo com as observações de Flower e Hayes (1981), os escritores frequentemente ativam seu conhecimento anterior para trabalhar com representações e objetivos disponíveis em sua memória, a partir das quais, durante o processo de produção de texto, podem criar novos conhecimentos ou reformular os antigos. Objetivos mais gerais são hierarquicamente superiores aos mais específicos. Assim, o procedimento de planejamento requer do escritor competência para a organização dessas representações, para identificar categorias, buscar ideias subordinadas para desenvolver o tópico ou ideias mais amplas que englobem o tópico em desenvolvimento, identificar os tópicos iniciais ou finais, estabelecer sequências e distinguir os procedimentos típicos de composição do gênero de texto em construção.

Flower e Hayes (1981) observaram também que os escritores mais experientes, portanto, aqueles que responderam mais satisfatoriamente à demanda pelo texto, estabelecem objetivos para todos os aspectos do problema retórico e durante o processo voltam-se para eles e os reformulam ou criam novos objetivos. 
Concluíram também que uma rica rede de objetivos auxilia o escritor a produzir novas ideias, a criar.

Cada situação de produção pode gerar diferentes dinâmicas de acionamento do procedimento de planejamento, que é constituído por atividades que o escritor desenvolve em diversos âmbitos do processo discursivo. Essas atividades de planejamento são representações que o escritor elabora do problema retórico, do interlocutor, dele próprio como autor, do texto (em seu aspecto formal, material) e do conteúdo.

0 planejamento parece ser, assim, uma experiência de autoria que podemos acumular ao longo do exercício da escrita. E, também, podemos ensiná-lo, de modo a ajudar os estudantes a aprimorar a elaboração de textos. Porém, é importante lembrar que o planejamento não constitui uma atividade pré-escrita, mas é procedimento utilizado pelo autor durante todo o processo de produção de texto.

\subsection{Procedimentos de produção de texto}

Ao escrever, com o intuito de conferir sentido ao texto em construção, o escritor organiza e põe em prática um conjunto de saberes de modo a resolver conflitos e estabelecer estratégias para lidar com possíveis restrições linguísticas e extralinguísticas, conectar seu texto à realidade e atingir seus objetivos.

Possenti (2001) parte do pressuposto de que existe estilo em qualquer linguagem simplesmente porque toda linguagem é produto do trabalho de seus usuários, resultado da escolha entre diferentes possibilidades de representação do conteúdo.

É, portanto, possível:

[...] ver estilo tanto no poema mais originalmente elaborado e mais impressionante do ponto de vista estético, quanto num ofício individual escolhido entre milhares exatamente idênticos que uma secretária datilografa no curso de uma carreira, por mais que ela seja eficiente e burocrática, isto é, por mais que ela os execute uniformemente e retire deles qualquer resquício de falta de objetividade. Porque, afinal, um ofício é o resultado de um trabalho longo, destinado exatamente a apagar dele qualquer marca de individualidade, o que significa que é o resultado de uma ideia de forma que aos poucos se concretizou (mesmo esquecendo estrategicamente o fato de que os ofícios têm datas, destinatários e assinaturas, que os individuam) (p. 247-248). 
Ainda de acordo com Possenti (2001), as escolhas efetuadas no interior de uma língua podem ser avaliadas considerando-se duas ordens de elementos: a diversidade dos recursos expressivos e o valor social e estético atribuído a eles. Nessa atividade de atribuição de sentido, também há que se distinguir o papel da coletividade e do indivíduo na construção dos estilos.

Compreendemos, portanto, que as marcas de autoria se submetem a uma série de restrições sociais, contextuais e linguísticas. E que o sentido de um texto depende sempre muito fortemente das variáveis extralinguísticas, de acordo com contingências das situações de produção e de recepção. Por isso, não se pode dizer que o sentido está no texto nem fora dele, no contexto, mas nas relações de um com outro, enquanto prática social.

A construção de um texto, enquanto processo de produção, implica essa percepção global das variáveis que vão interferir na interpretação do escrito. Assim, um escritor, ao planejar seu texto, leva em conta o que conhece acerca das circunstâncias de seu trabalho, dos objetivos que tem, seja para responder ao problema inicial que incitou seu texto, seja sobre as estratégias linguísticas e extralinguísticas que pode utilizar para induzir a interpretação que fará o leitor, de modo a imprimir este ou aquele acento de significação no que escreve.

Entretanto, ainda que os fatores extralinguísticos sejam essenciais para a interpretação do sentido de um texto, é a forma linguística dada ao conteúdo que exerce função primordial, porque ela é a interface que permite o acesso do leitor ao discurso e a suas relações dialógicas. Além disso, a forma material do texto, que resulta de escolhas condicionadas pelo contexto de produção, é também, por si só, conteúdo que exigiu posicionamento do autor para sua construção.

A língua exerce forte restrição à autoria, pois representa o meio material em cujo âmbito o escritor se limita a operar. Desse modo, a materialidade sígnica delimita as possibilidades de representação. 0 gênero do texto é outra forte fonte de restrições à autoria, uma vez que, sob certo gênero, o escritor está submetido a uma esfera de circulação, a um público leitor, a temas possíveis, entonações e estruturas composicionais e estilísticas típicas.

É no âmbito dessas restrições que o escritor trabalha. É com essas restrições que necessita negociar enquanto escreve. Nesse sentido, ter competência escritora é saber gerenciar essas restrições, explorá-las e até transgredi-las. Para tanto, é preciso conhecê-las. A autoria é um procedimento intencional, não um acaso. 
De um modo geral, ao ler diversos textos de um mesmo escritor, é sempre possível reconhecer um certo modo de dizer que, por se repetir regularmente, torna-se típico e, portanto, pode ser considerado marca de autoria. Observamos o uso repetido de expressões, ou de certo encaminhamento lógico, ou o uso excessivo de subordinação ou de determinados tipos de conectivos, enfim, recursos sintáticos ou morfológicos que acabam por individualizar o texto em função da regularidade com que essas marcas aparecem. Essa singularidade sintática pode ser reconhecida como marca de autoria.

É comum, por exemplo, professores reconhecerem textos de seus alunos e até mesmo quando um deles copia um texto alheio e o apresenta como seu. Devido à frequência com que lê textos dos estudantes, o professor acaba por identificar autorias, mesmo de modo intuitivo, porque reconhece suas regularidades sintáticas, entre outras.

No nível dos textos, a escolha do gênero é indicativa de uma intenção. Tecer uma crítica por meio de uma fábula, de uma crônica ou um artigo estabelece, em princípio, diferenças principalmente quanto ao tom do que se diz. A fábula pode dar à crítica um tom mais didático, enquanto a crônica pode apelar para o humor ou a ironia e o artigo para o raciocínio lógico, por exemplo.

Além disso, cada gênero se estrutura com base em certas sequências textuais que podem ser organizadas segundo os objetivos do escritor. Não há, por exemplo, um modo único de contar histórias. Um romance pode ter a linearidade temporal da narrativa de fatos alterada. Um policial, em vez do enredo tradicional, pode apresentar logo no início da sequência narrativa o crime desvendado para depois elucidar como foi cometido. Ou pode recontar uma mesma sequência de acontecimentos sob o ponto de vista de mais de um personagem. Cada gênero possibilita inúmeras atuações do escritor em busca da forma mais adequada para a produção de sentido que mais bem cumpre seus objetivos.

Todo escritor possui um repertório de estratégias e recursos linguísticos adquirido por meio da leitura de outros escritores e da própria experiência com a produção de textos. Porém, cada texto é único, de modo que os escritores precisam ter agilidade para reformular ou reinventar essas estratégias a cada texto que produzem.

Encontrar a forma adequada para representar o conteúdo é, de certa forma, compatibilizar os recursos que darão ao texto sua condição de textualidade em resposta aos objetivos estabelecidos. 


\subsection{Procedimentos de revisão}

Segundo Sommers (1994), as concepções que entendem o processo de produção de textos como uma sucessão linear de etapas distintas (pré-escrita/escrita/revisão) tratam a revisão como uma etapa isolada, que ocorre ao final do processo de escrita, depois do primeiro ou segundo rascunhos. Assim compreendida, a revisão não passa de uma atividade de reescrita, uma ampliação do que já está no rascunho, uma atividade supérflua e redundante (Sommers, 1994).

Ao examinar o processo de produção de textos de estudantes e escritores experientes, Sommers (1994) verificou que a revisão é um procedimento que ocorre durante toda a composição: "a sequence of changes in a composition - changes which are initiated by cues and occur continually throughout the writing of a work" 5 (p. 77). As operações de revisão realizadas pelos escritores participantes da pesquisa foram o apagamento, a substituição, a adição e a reordenação. 0 estudo também revelou que esses procedimentos incidiam sobre diferentes níveis do texto: a palavra, a frase, o tema (compreendido como uma declaração desenvolvida de uma ideia).

Sommers (1994) observou que os escritores menos experientes compreendiam a revisão como processo que incidia apenas sobre alterações lexicais, não semânticas. Esses escritores determinavam a extensão de sua revisão em função de seu nível de "inspiração". Usavam se referir à "inspiração" para descrever o grau de dificuldade com a qual seus ensaios eram escritos e o quanto necessitavam ser revisados. Caso se sentissem inspirados, se a escrita fluísse facilmente, não viam necessidade de revisão (Sommers, 1994).

Diferentemente, os escritores mais experientes concentravam as mudanças no nível das sentenças, mas realizavam mudanças em todos os níveis e usavam todas as operações de revisão. Além disso, possuíam uma teoria acerca do processo de escrita em sua totalidade, com a percepção da revisão enquanto processo recursivo. A revisão do estilo, geralmente realizada pelos escritores experientes, ocorria mais ao final do processo (Sommers, 1994).

Os procedimentos de revisão observados nesse estudo podem ser considerados auxiliares da composição, na medida em que, assim distribuídos por todo o processo, permitem ao escritor mais bem administrar as demandas e se concentrar nelas de forma organizada, elegendo o foco da revisão a cada momento.
5. "uma sequência de alterações na composição - mudanças que são iniciadas por pistas e ocorrem continuamente no curso da escrita de um trabalho" (tradução da autora). 
Essas observações nos permitem avaliar a revisão como um conjunto de procedimentos que visa ajustar a forma do texto aos objetivos do escritor. Do ponto de vista de que toda atividade de atribuição de forma a um conteúdo é, por si só, um ato de individualização do enunciado e, portanto, um procedimento de autoria, a revisão é atividade privilegiada do escritor porque tem por objetivo primeiro a atribuição de forma do texto em todos os níveis.

A revisão funciona, portanto, como atividade de reflexão, momento em que o escritor se distancia do objeto criado para analisar o que foi feito e planejar novos ajustes no escrito. Esse movimento envolve a leitura crítica do texto. É então que compreendemos uma das maneiras como a leitura e a escrita podem interagir na produção de um texto. São os processos de revisão que acionam a leitura e a tornam auxiliar da escrita. A competência leitora do escritor exerce nesse momento papel fundamental, pois, ao ler o seu próprio texto, leva em conta o conhecimento acumulado de textos lidos anteriormente como referência para a análise crítica. É por meio desse diálogo entre o texto em produção e o repertório de textos acumulado que o leitor educa o escritor.

Poderíamos arriscar a hipótese de que a experiência de escrita também educa o leitor, já que, ao ler, ele pode acessar o conjunto de experiências que tem de escrita, as estratégias de construção de texto adquiridas ao longo do tempo. Recorrendo a essas experiências de produção de texto durante a leitura de qualquer texto, pode observá-lo do ponto de vista do escritor, e então analisar sua arquitetura e reconhecer suas estruturas e construções, observando as formas escolhidas. Pode, dessa forma, ler o texto pelo seu "avesso". Essa experiência se adquire com o exercício de revisão porque é o momento em que o escritor concentra maior atenção na forma do texto.

A revisão, procedimento de autoria por excelência, reúne as ferramentas mais valiosas para a atividade de escrita porque obriga o escritor a observar a forma, a buscar uma estética que mais bem responda aos seus objetivos, a moldar o seu texto experimentando diferentes recursos, a manipular o signo e a mais bem conhecê-lo. A revisão ensina o escritor a compreender que um texto é uma construção complexa porque envolve todo o conhecimento de que dispõe. 


\subsection{Procedimentos de gestão de processos}

Segundo Flower e Hayes (1981), ao escrever os escritores monitoram o processo de escrita em andamento e seu progresso. Esse é um trabalho que ocupa a atenção do escritor durante todo o processo de composição de textos, articulando a produção em desenvolvimento e os procedimentos de controle do discurso (Foucault, 2000), tanto externos como internos.

Em função da sobrecarga cognitiva que essa gestão de processos pode acarretar, alguns pesquisadores desenvolveram estudos de modo a compreender como "aliviar" essa carga de trabalho dos escritores e tornar a tarefa de escrita mais produtiva. Nesse sentido, estratégias de planejamento têm sido analisadas, com o pressuposto de que, gerando ideias e organizando sua distribuição previamente, é possível diminuir a sobrecarga de trabalho durante a composição.

Kellogg (1988) distinguiu duas maneiras de evitar essa sobrecarga cognitiva: com a elaboração de um plano geral ou um esquema do texto a ser escrito ou com a elaboração de rascunho. A primeira estratégia tem o propósito de auxiliar o escritor a gerar ideias e a organizá-las antes de escrever. A segunda implica a produção de um rascunho no qual o escritor anota tudo o que the vem à cabeça, sem se preocupar com a forma do texto.

Segundo Torrance e Galbraith (2004), quando o planejamento do texto antecede a escrita, pode ocorrer a separação dos procedimentos de planejamento e os de escrita do texto, o que não é desejável. Quando o processo de composição se inicia pelo rascunho, a preocupação com a forma do texto é deixada para outra etapa do processo. Essa segunda estratégia separa, portanto, a escrita da revisão. Além do mais, entendemos que essa segunda proposição resulta de um equívoco: ela não leva em conta que a forma é também um conteúdo e que também gera sentido.

Em qualquer dos casos, essas estratégias podem representar perdas no processo de produção de texto, se compreendermos que é a interação entre os diferentes processos que amplia as possibilidades criativas do escritor.

Segundo Torrance e Galbraith (2004), pesquisas envolvendo essas duas estratégias concluíram que a construção hierárquica e organizada de um plano geral do texto antes do início da composição esteve mais frequentemente associada à produção de textos de melhor qualidade. Esse resultado talvez se deva, em parte, à otimização do uso da memória de trabalho, central executiva que 
gerencia todo o processo em desenvolvimento, em decorrência da antecipação do trabalho realizada pelo planejamento.

Estratégias que consistem em escrever tudo o que se sabe sobre o assunto para depois editá-lo exigem um escritor mais experiente, porque desencadeiam uma tarefa de revisão não apenas linguística, mas do texto como um todo, do dito e do implícito, da forma e dos objetivos. Por outro lado, pretender escrever o texto de uma única vez, conforme as ideias surgem, pode ser uma estratégia ingênua que ignora as particularidades da escrita, especialmente os benefícios da revisão. 0 gerenciamento do processo e, portanto, da distribuição da carga de trabalho de forma mais produtiva pode ter, como resultado, textos qualitativamente mais bem escritos.

Segundo Flower e Hayes (1981), o conhecimento a que se tem acesso pela memória e os planos do escritor para tratar o problema retórico são fontes de conflito. A todo momento podem surgir demandas originadas do confronto entre o que o escritor sabe acerca de um tópico e o que é possível dizer a um dado leitor; ou entre uma forma estilística que visa à estética do texto e um conteúdo complexo que o escritor deve desenvolver. Muitos dos problemas que bloqueiam a escrita podem ser causados pelo modo como escritores contornam ou incorporam as múltiplas restrições colocadas por seu conhecimento anterior, seus planos e seu texto, no momento da produção escrita.

A resolução de um conflito dessa natureza requer, muitas vezes, o desdobramento do processo de produção, pois um problema pode suscitar a geração de novas ideias que necessitam ser organizadas, escritas, revistas e depois inseridas na estrutura mais abrangente do texto que está sendo escrito. 0 processo de produção do texto acaba por integrar vários subprocessos, de forma recursiva, e, dada sua complexidade, necessita ser gerenciado. E um bom trabalho de gestão pode auxiliar o escritor a desempenhar de forma produtiva sua tarefa. É por isso que um plano geral do texto, que estabeleça níveis hierárquicos do desenvolvimento do conteúdo e admita muitas sub-rotinas vinculadas, permite ao escritor coordenar diversos objetivos a partir de poucos processos, porque essas sub-rotinas estarão vinculadas aos procedimentos básicos de planejamento, redação e revisão.

No entanto, essa é uma forma de administrar a tarefa que requer cuidado, porque o planejamento que pretenda antecipar todo o texto pode funcionar como uma restrição à produção, um 
forte mecanismo de controle gerado pelo próprio escritor e que pode inibir a produção.

Flower e Hayes (1981) observaram que, embora os escritores percebam seus processos de escrita como desorganizados ou desestruturados, os procedimentos que usam têm sua própria base de coerência, direção e propósitos. E muitos objetivos novos ou reformulados a partir dos anteriores alimentam a geração de ideias e um novo ciclo de planejamento e organização que provoca mais escrita e revisão, numa alternância constante entre os procedimentos. Portanto, tentar resumir todo o processo em um único planejamento inicial é inibir o desenvolvimento do fluxo de texto.

Para concluir, é interessante lembrar a observação feita por Levy e Ransdell (1996) a respeito da forma como os escritores podem administrar o tempo de planejamento, produção e revisão de texto, mantendo um modus operandi muito próprio, pessoal. Essa marca pessoal de gestão de processo é uma "assinatura" do escritor.

Sob esse ponto de vista, cada escritor desenvolve um comportamento típico que se traduz na maneira como integra os procedimentos de planejamento, produção de texto e revisão, como administra as restrições externas e internas ao discurso e como conduz a dinâmica do processo de gestão (a organização, a distribuição e a coordenação dos procedimentos de escrita). Da complexa interação de procedimentos de planejamento, produção e revisão surgirá o seu estilo, sua "assinatura de escritor".

\section{REFERÊNCIAS}

BAKHTIN, M. O problema do conteúdo, do material e da forma na criação literária. In: Questões de literatura e de estética. A teoria do romance. Tradução Aurora Fornoni Bernardini et al. 5. ed. São Paulo: Hucitec, 2002, p. 13-70.

. 0 autor e a personagem na atividade estética. In: BAKHTIN, M. Estética da criação verbal. Tradução Paulo Bezerra. São Paulo: Martins Fontes, 2003a, p. 3-192. (Original russo, 1920-1930)

. Os gêeneros do discurso. In: BAKHTIN, M. Estética da criação verbal. Tradução Paulo Bezerra. São Paulo: Martins Fontes, 2003b, p.261-306. 
- O problema do texto na linguística, na filologia e em outras ciências humanas. In: BAKHTIN, M. Estética da criação verbal. Tradução Paulo Bezerra. São Paulo: Martins Fontes, 2003c, p.307-335.

Problemas da poética de Dostoiévski. Tradução Paulo Bezerra. Rio de Janeiro: Forense Universitária, 2005.

FLOWER, L.; HAYES, J. R. A Cognitive Process Theory of Writing. College Composition and Communication, USA, v. 32, n. 4. p. 365-387, dez. 1981.

The cognition of discovery: defining a rhetorical problem. In: PERL, Sondra (Org). Writing Process. Davis (CA,USA): Hermagoras, 1994, p. 63-74.

FOUCAULT, Michel. A Ordem do Discurso. Tradução Laura Fraga de Almeida Sampaio. 5. ed. São Paulo: Loyola, 2000.

KELLOG, R.T. Attentional overload and writing performance: effects of rough draft and outline strategies. Journal of Experimental Psychology: Learning, Memory and Cognition. USA: American Psycological Association. 1988, v. 14, p. 355-365.

LEVY, Michael C.; RANSDELL, Sarah. Writing Signatures. In: The science of writing: theories, methods, individual differences and applications. Mahwah (NJ, EUA): Lawrence Erbaum Associates, 1996, p. 149-161.

MOLITOR-LÜBBERT, Sylvie. A escrita como um processo mental e linguístico. In WIESER, H. Peter; KOCH, I. G. Villaça (Org.). Linguística textual: perspectivas alemãs. Rio de Janeiro: Nova Fronteira, 2009, p. 121-165.

POSSENTI, Sírio. Discurso, estilo e subjetividade. São Paulo: Martins Fontes, 2001.

SOMMERS, Nancy. Revision Strategies of Student Writers and Experienced Adult Writers. In: PERL, Sondra (Org). Writing Process. Davis, California,USA: Hermagoras, 1994, p. 75-84.

TORRANCE, M.; GALBRAITH, D. Revision in the context of different drafting strategies. In: L. Allal, L. Chanquoy, \& P. Largy (Eds.). Revision of written language: cognitive and instructional processes. Amsterdam: Kluwer, 2004, p. 63-86. Disponível em www.staffs.ac.uk/personal/sciences/ mt15/publications/GT01_revision.pdf. Acesso em 06 out. 2008.

TYNJÄLÄ, Päivi; MASON, Lucia (Orgs.). Writing as a Learning Tool. Netherlands: Kluwer Academic Publishers, 2001, 219p. (Studies in Writing, v. 7). 